\title{
EXPANDING BROADCASTING THE (R)EVOLUTION OF BROADCASTING AND THE ROLE OF NEW COMMUNICATORS IN THE NEW DIGITAL ERA
}

\author{
Irene Giannara \\ Andreas Giannakoulopoulos ${ }^{1}$
}

The Internet is a critically important research field for sociologists and communication theorists testing theories and communication models of technology diffusion and media effects, particularly because it is a medium uniquely capable of integrating modes of communication and forms of content.

The Internet presents researchers with a moving target: Agre (1998a) describes it as « a meta-medium : a set of layered services that make it easy to construct new media with almost any properties one likes ». We use Internet to refer both to technical infrastructure (public TCP/IP networks, other large-scale networks, and foundational protocols), and

1 Irene Giannara is Journalist and Media Developer, University of Athen. Andreas Giannakoulopoulos is professor at the University of Athen.

Special acknowledgments to Miss. Maria Kalyviotou and Mr. Kostantino Arakosta students of the Dept. of Communication and Media Studies, University of Athens who participate as researchers at this project.

Recherches en communication, $\mathrm{n}^{\circ} 26$ (2006). 
to uses to which this infrastructure is put (World Wide Web, electronic mail, online multiperson interactive spaces).

The medium's rapid growth offers an once-in-a-lifetime opportunity for scholars to test theories of technology diffusion and media effects. Internet is unique because it integrates both different modalities of communication (reciprocal interaction, broadcasting, individual reference-searching, group discussion, person/machine interaction) and different kinds of content (text, video, visual images, audio) in a single medium. Finally, choices are being made-systems developed, money invested, law passed, regulations promulgated-that will shape the system's technical and normative structure. Many of these choices are based on behavioural assumptions about how people and the Internet interact.

\section{Theoretical Context}

Sociology's recent theoretical tradition offer perspectives on the digital media. Technological determinists suggest that structural features of new media induce social change by enabling new forms of communication and cultivating distinctive skills and sensibilities (McLuhan 1967, Eisenstein, 1979).

Daniel Bell (1977) appears to have been the first sociologist to write about the social impact of digital communications media themselves. Bell explored the policy dilemmas these changes would raise, calling «the social organization of the new 'communications' technology » the most central issue « for the postindustrial society » $(1977: 38)$.

More recently, Manuel Castells has argued that the world is entering an « information age » in which digital information technology «provides the material basis » for the «pervasive expansion » of what he calls « the networking form of organization » in every realm of social structure (1996 : 468). According to Castells, the Internet's integration of print, oral and audiovisual modalities into a single system promises an impact on society comparable to that of the alphabet (p.328), creating new forms of identity and inequality, submerging power in decentered flows, and establishing new forms of social organization.

The comprehensive visions of Bell and Castells suggest a range of empirical questions one must answer to understand the Internet's influence upon society. Critical theory raises important questions of how the Internet may affect the arts and entertainment media. 


\section{Impact on Time Use and Community : Social Isolation or Social Interaction}

Much of the debate over social capital is about whether the Internet attenuates users' human relationships, or whether it serves to reinforce them. Experience with earlier communications technologies suggests that Internet users may substitute time online for attention to functionally equivalent social and media activities (Weiss 1970).

The situation with respect to social interaction is far more complicated. Two well-publicized studies reported indications that Internet use substituted for other interactions. Kraut et al (1998), reported that higher levels of Internet use were « associated with declines in communication with family members, declines in social circles, and increased loneliness and depression. » The authors inferred that heavy users substitute interactions with weak ties on the Internet for time spent with close friends and relatives. Yet as the researchers followed their sample they discovered that, except for increased stress, negative psychological effects decayed to statistical insignificance and some positive outcomes emerged. They attribute these changes to increase in experience and competence and, more speculatively, to the Internet's greater utility in the later period and to a change in sign of network externalities from negative to positive as more of these users' friends and family went online (Kraut et al., 2000)

\section{Impact on Culture : Hypersegmentation, or Massification?}

Many sociologists feared that the conventional mass media (generalinterest magazines, radio, and television) would inexorably "massify" taste, as profit-seeking firms produced only those homogeneous and predictable programs or texts with the greatest audience appeal (Shils 1963). Since 1980, changes in consumer demand have combined with new media technologies to segment markets and differentiate cultural goods, enabling individuals and groups to individualize their media habits. As an «interconnected network of audio, video, and electronic text communication that will blur the distinction between interpersonal and mass communications and between public and private communications » (Neuman 1991, p.12), the Internet seems designed to take these trends to their logical conclusion.

Not surprisingly, early observers viewed the new technology as profoundly liberating, opening up outlets for the creative energies of 
people of every taste and persuasion (Barlow 1996). Because posting information on the Web is so inexpensive, the technology's enthusiasts believed it would virtually eliminate barriers to entry in fields like music recording, book publishing, and film making. In this view, the Internet would democratize the flow of information, supplanting topdown dependence on traditional news and media organizations with bottom-up sharing among consumers themselves.

Such optimistic scenarios assume that the Internet's only impact is a direct one on costs (of cultural goods to consumers and of publication to producers). But a second, perhaps more important, effect of the Internet may be to induce the restructuring of the culture industries themselves. When goods are distributed on the Internet, they can be repackaged in many ways. New distribution systems also alter the size distribution of firms within industries, the relative power of gatekeepers and artists, and the nature of competitive strategies. The Web's earliest cultural impact has been in the music industry, where it has reinforced existing trends towards deconcentration, product differentiation, and the multiplication of market channels (Dowd 2000, Caves 2000).

The Internet's cultural effects may vary among user groups. Because marketers are most interested in reaching people who consume the most, their "fragmenting" efforts may focus on the well-to-do; but such users, especially when they are highly schooled, are the ones most likely to use sophisticated search strategies, so their online behavior may be less easily affected. Castells (1996: 371) predicts a Web « populated by two essentially distinct populations, the interacting and the interacted », the first using the medium's full capacity, the latter limited to a « restricted number of prepackaged choices ».

\section{The Research}

Main aim of the research that is carried out among the undergraduates students of the Department of Communication and Media Studies of the University Athens is : a) to determine the basic behavioural characteristics of the young internet users, appreciating the frequency and the type of use of computers and internet, b) to investigate the degree of entanglement of media studies students in Greece, with the radio and the new technologies, since the students of the aforementioned Department will constitute the future generation of journalists that will staff the sector of mass media in Greece, c) to examine the connection of music with new technologies and the internet in their everyday life, d) to study 
the representation of the communicational model used in conventional media within the New Media, and e) to study the representation of the user' s interaction with the social context within the New Media. At this point it must be mentioned that the following results concern only the $50 \%$ of the questionnaires filled for the purposes of this research.

In the questionnaire particular emphasis was given in :

a) the level of studies as the students of Department [EMME] are introduced to the use of the new technologies during their first year of studies,

b) the place of origin and in their financial status as the students that come from the district/rural areas experience during their first year of studies a relative isolation, as a transitional period of adaptation, which guides them in the search of more personalized forms of entertainment, particularly with the use of computers and the internet.

Furthermore the research will try to appreciate the degree of familiarization of the students that come from urban centers in equivalence with the students from the rural regions with the new technologies and the internet. With regard to their financial status particular interest existed in the answers as most students are unemployed, or part time occupied with low incomes.

All questioned students affirm that they use the internet (100\%) daily $(68 \%)$, more than one hour per day $(63,2 \%)$ and for more than one year $(89,5 \%)$. They connected mainly from their house $(98,2 \%)$.

The provided internet services used more by the students are : the e-mail, online games and the internet radio ${ }^{1}$, chat, blogs, the FTP and the $\mathrm{RSS}^{2}$, while important number of questioned students shows particular preference in the search engines, forums, and the downloading. From the compositional elements of a web page they emphasize more on the content and the design and less on the search options and the ability to communicate with other users.

The majority of the questioned students does not use programs of files distribution in a percentage of $53,6 \%$. While the $33,2 \%$ exchanges via $\mathrm{P} 2 \mathrm{P}$ programs music $(42,1 \%)$ and image $(31,6 \%)$ files. In addition, the vast majority knows what is MP3 $(98,2 \%)$, while particular interest

1 Here, it must be noticed that the Department of Communication and Media Studies has a very popular, among the students, Web Radio in which students participate with their radio programs (speech and music programs).

2 The presentation of the provided services is in decrease order. 
presents the fact that more than half of the questioned students know that MP3 are low quality music files. (53\% Yes, $46,4 \%$ No).

In the question about the medium of listening they use on daily base the first place in their preferences possesses the radio and follows the CD Player, the MP3 Player, the television (with the form of music programs and video clips), the Internet, surprisingly the Pick Ups, the cassette players, the computer and the DVD.

Commonly they have in their possession CD Player (94,7\%), domestic sound system $(78,9 \%)$, portable sound system $(71,9 \%)$, mobile telephone with MP3 Player $(61,4 \%)$, sound system connected

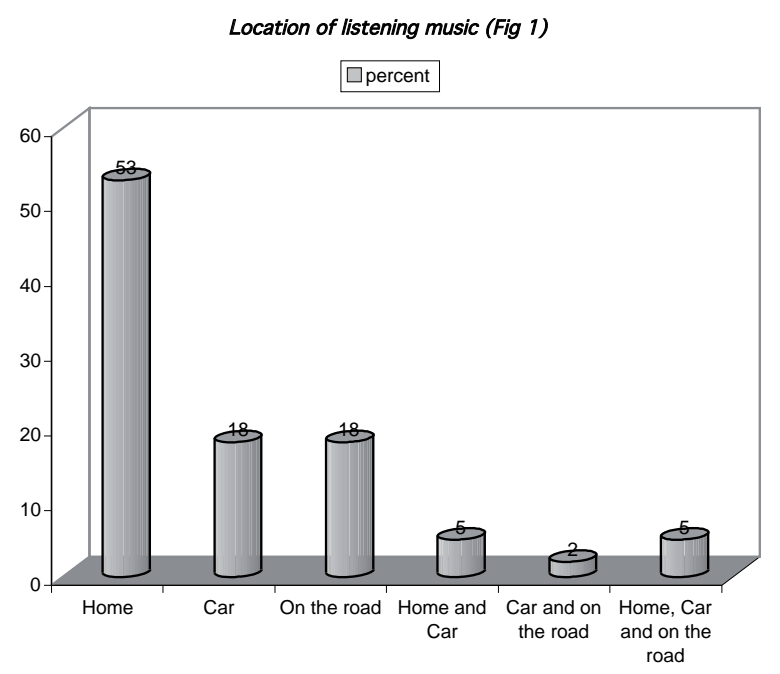

with PC (54,4\%), MP3 Player (52,6\%), portable tuner (21\%), mobile telephone with radio $(3,5 \%)$.

Important element in this question is the small percentage appeared to own an iPod device $(14,0 \%)$. As explanation to that was given the cost of purchase of the device, the cost of the downloading files as well as the weakness to transfer files in other devices.

In the question about where they listen more music the majority mentioned the house in percentage $52,6 \%$ with the use of radio in percentage $48,6 \%$. The $17,5 \%$ answer that it listens more in the car using once again the radio in percentage $68,8 \%$. From the percentage of those who they listen music via portable appliances music devices 
$(17,5 \%)$ prefers portable MP3 devices in percentage $57,1 \%$ and radio in percentage $35,7 \%$. (figure 1 )

In the general question if they listen to the radio $98,2 \%$ answered positively. The $93 \%$ answered that it listens daily with particular preference in music programs $(61,4 \%)$ concerning modern Greek music $(73,7 \%)$, national folk music $(71,9 \%)$ and international repertoire [rock
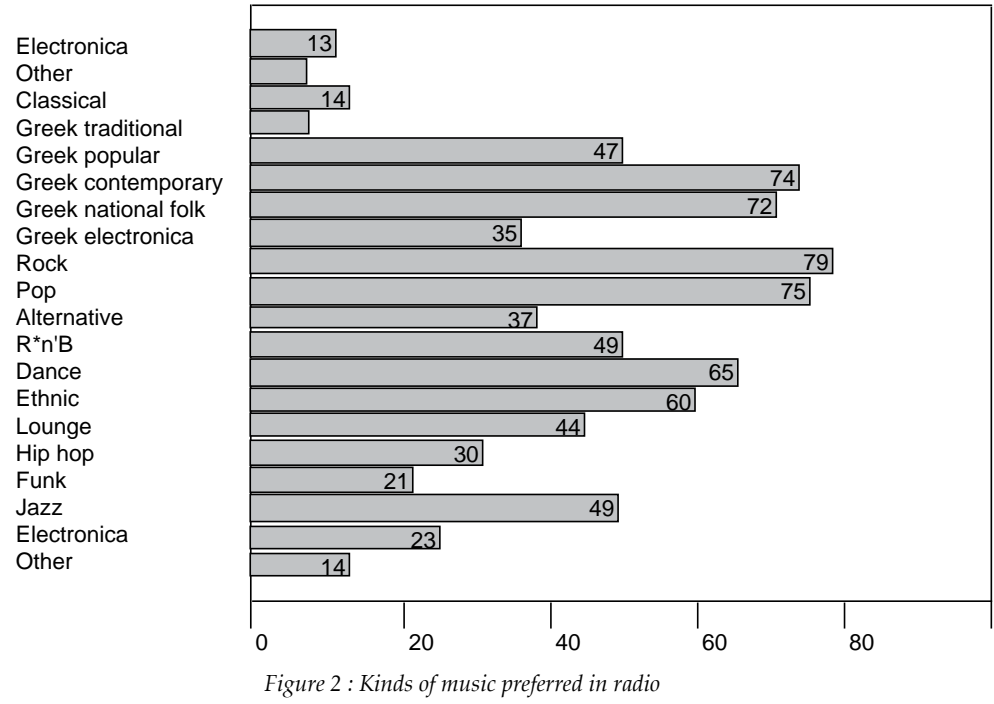

(78,9\%), and pop music $(75,4 \%)]$. (figure 2$)$

When they questioned if they have ever contacted with a radio station or a radio presenter the majority answered negatively $(59,6 \%)$. While those who answered positively in the question clarified that the communication with the station or the radio presenter was via phone call $(26,3 \%)$ and SMS $(22,8 \%)$.

Their preferences on radio programs are guided by : the content of music choices, the way of presentation, the voice of the radio presenter, the subjects presented in the program, the participation of the listeners, the absence of advertisements from the program of station and the character of the radio presenter. Also they are paying attention to the style of radio station, the news reports and the competitions.

In the question if they listen radio via the internet $42 \%$ answered negatively, the $42 \%$ answered that listens occasionally and the $15,8 \%$ answered positively. The programs that they prefer are music oriented and are referable the changes in the percentages of music genres that 


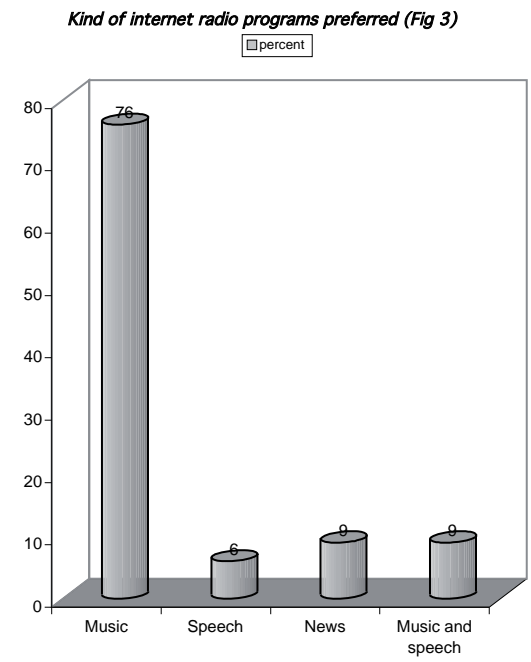

they prefer listening. In conclusion it can be said that listening music via internet becomes more collective and fragmentary probably because of the ability of the medium for multiple searches. (figure 3)

Another important element concerning the behavior of the internet audience is the fact that the majority questioned, has recommend a radio program to friends $(69,6 \%)$. This possibly indicates a tendency of co-listening, even if the medium does not supports this tendency according to the characteristics that it had in the conventional radio. In the conventional radio the listener was experiencing the act of listening in concrete space and time intervals. In Internet radio there is a fragmentation of time and space which isolates the program from the audience and vice versa.

Will you be interested in a radio program personalised?

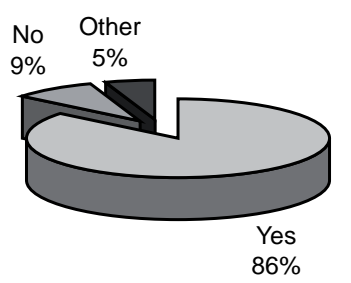

Personalized radio program and audience preferences

(Fig 4) 
Grades of Webradio attributes (Fig 5)

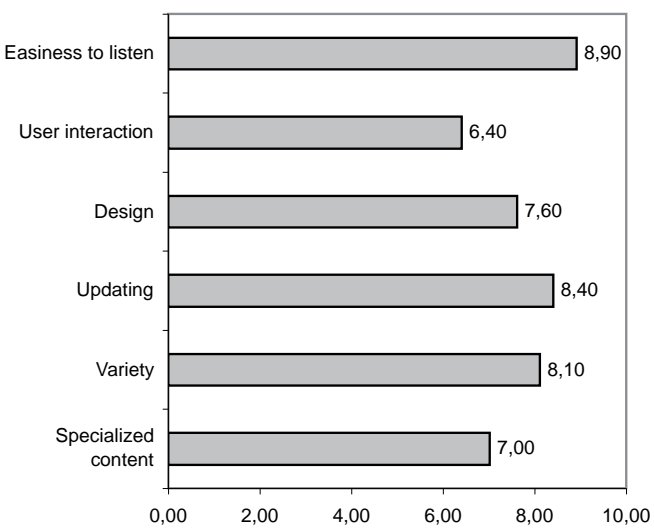

Internet radio has strengthened more the significance of personal listening which releases the listener from the significance of time of programmed duration of radio program. This option is reinforced by the answers given when the questioned if they would be interested in a radio station with content adapted in their personal preferences. Here majority $(86 \%)$ answered positively, while others $(5,3 \%)$ consider that the variety of program is satisfactory independently from their personal preferences. (figure 4)

In the question what interests them in an internet radio web page the majority referred to the quality of sound, the easiness of listening, the ads for work, the design of the web page, the updating and the variety

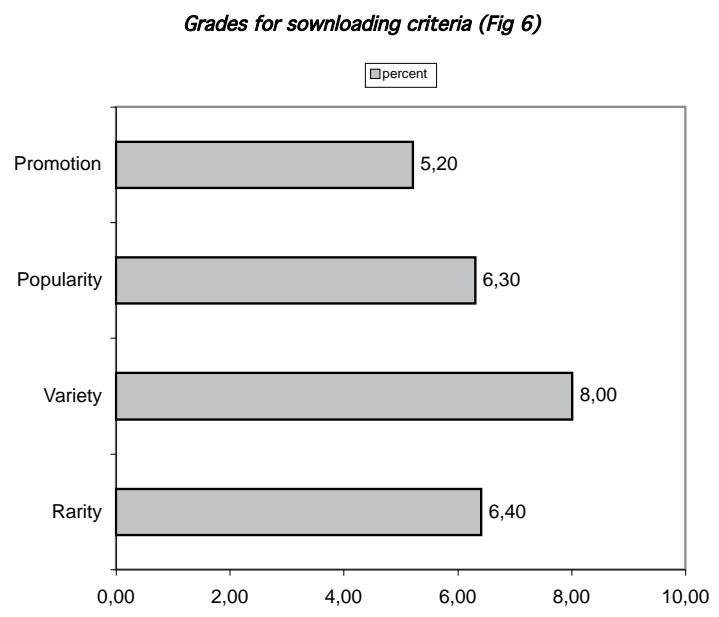




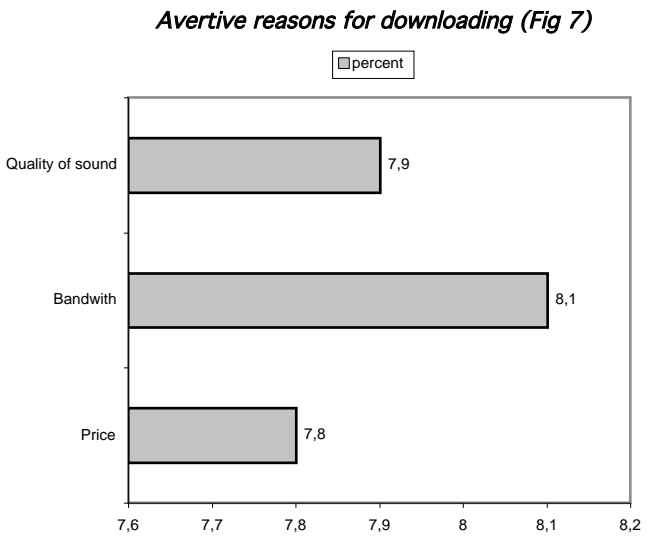

of the content, the specialized content and the interaction with other users. (figure 5)

Crushing is the percentage of the asked students that downloads songs or radio programs in their portable MP3 Player or in their PCs $(59,6 \%)$. The criteria for downloading a song or a radio program are determined from : the variety of repertoire, its rarity, its popularity and its publicity. (figure 6 )

Despite the fact that they download music files in big percentage they do not share them with friends or other users (50,9\%). Finally the reasons that render deterrent the downloading or the exchange of music file are reported in the speed of the network in Greece, in the quality of files and in their price (they consider that the relation of the price in regard with the quality of the shared files is disproportionate). [figure 7]

\section{Conclusions}

The young internet users in Greece despite their pastime with the internet and the new technologies prefer the classic methods of listening. This can be justified from the high cost of the internet services and from the high tariffs of the internet providers in Greece. This phenomenon cannot be characterized as technological illiteracy of the new users, more it characterizes the policy of Greece in the sector of new technologies.

- With regard to the phenomenon of social isolation through the use of new technologies in Greece we can say that still not intense elements of social isolation are observed, at least as long 
as this becomes obvious in other European countries. Since the internet users do not seem to follow blindly the fashion of this new medium in anything relating to activities, interaction and entertainment. Additionally they can be described as "conscious searchers of information", than as individuals that shape their everyday life through the internet.

- However, mass media in Greece are featured with isolation as it appears that the new listeners are not satisfied from their basic characteristics as the content or the specialisation of radio programs. This leads progressively to the search of new forms of listening.

- Massification and hypersegmentation in communication and the everyday life of young persons appears that it is influenced more by the conventional media, than from the use of internet. Mass Media and the industry of entertainment show that they have not comprehended the new, financial and social, formation of the audience they addressed to. In fact, they prove that they are unable to correspond to the requirements of the new medium and the new internet culture thus as it is shaped in world scale. In opposition the users of internet, specifically with regard to the music, prove that they become stricter in their choices, seeking of genres of music and types of information that probably they do not receive from the conventional media. This can be characterized as a healthy reaction toward the abundance of information diffused in the internet and the offered choices.

\section{References}

Agre P. 1998a. The Internet and public discourse. First Monday 3. http://www.firstmondaydk/issues/issue3_3/agre/index.html Barlow JP. 1996. A Declaration of the Independence of Cyberspace http://www.eff.org/ barlow/Declaration-Final.html

Bell D. 1977 [1980]. Teletext and technology : new networks of knowledge and information in postindustrial society. In The Winding Passage : Essays and Sociological Journeys. 1960-1980, ed. Bell, pp 34-65. New York : Basic

Castells M. 1996. The Rise of the Network Society. Vol.1 of The Information Age : Economy, Society and Culture. Oxford, UK : Blackwell's

Caves R. 2000. Creative Industries : Contracts Between Art and Commerce. Cambridge : Harvard Univ. Press 
Dowd T. 2001. Musical diversity and the mainstream recording market, 1955-1990. Rassegna Italiana di Sociol.

Eisenstein EL. 1979. The Printing Press as an Agent of Change. Cambridge Univ. Press

Kraut R, Patterson M, Lundmark V, Kiesler S, Mukophadhyay T, Scherlis W. 1998. Internet paradox : A social technology that reduces social involvement and psychological well-being? Am.Psychol. 53 : 1011-31

Kraut R, Kiesler S, Boneva B, Cummings J, Helgeson V. 2001. Internet paradox revisited. J.Soc. Issues.

McLuhan M. 1967. Understanding Media : The Extensions of Man. New York : McGraw Hill

Neuman WR. 1991. The Future of the Mass Audience. New York : Cambridge Univ. Press

Shils E. 1963. The theory of mass society. In American as a Mass Society, ed. P Olson, pp. 30-50. Glencoe, IL : Free Press

Weiss R. 1970. Effects of mass media of communication. In Handbook of Social Psychology, ed. G Lindzey, E Aronson, 5 :77-195. Reading, MA : Addison-Wesley 